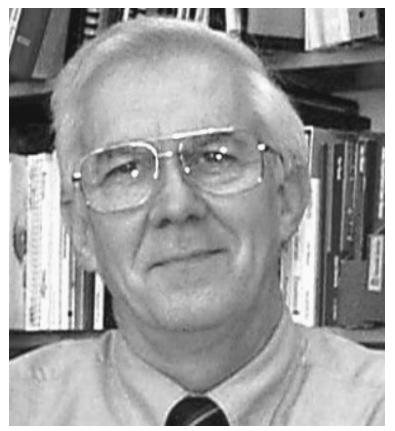

\section{The refractive index of optical engineers is one}

When H. G. Wells wrote The Invisible Man, his mechanism for creating invisibility was based on the supposition that body tissue, muscles, lungs, the digestive system, and the skeletal system were transparent and that it was the color of blood that allowed us to be able to see each other. The scientist in the story proceeds to develop an undisclosed technique for making blood transparent also. (Just nudge the Soret band into the UV!) The story takes a number of twists before the researcher, driven mad by his own treatment, is done in by the villagers. I ask my students to discuss the premise of the story, what might be wrong with it, and what might they do to make the story a little more realistic. Eventually they come to the conclusion that mirrors and lenses cannot redirect the light around the invisible person. The only way to make someone invisible would be to make a cloak and make everything within that cloak have a refractive index of unity and no visible absorption. Or perhaps create a potion that turns your body into the index of thin air.

Of course, if you are an optical engineer or scientist, you may already be invisible and not know it. In some countries an optical engineer is not considered a part of the workforce by a number of institutions whose recognition can make a difference. Right now the North American Industry Classification Systems, the National Science Foundation's (NSF) Survey of College Graduates, and the U.S. Department of Labor's Standard Occupations Classification (SOC) exclude any classification for optical engineer, optical scientist, or optical and electro-optical technician from their lists. So what's the big deal? The lack of an appropriate job category in the optics field can make it difficult to hire an engineer and scientist with optical specialties because of hiring practices. How many times have you heard about a colleague or student turning into an electrical engineer at the company gate in order to take a job?

This need for recognition comes at a time when our field is booming. Because of the increasing use of optical products and technologies in a wide range of applications, the optics industry-defined broadly-is maturing and growing rapidly. Only a little over a decade ago, optics was primarily a "cottage industry" with mostly small, entrepreneurial companies doing predominately government-funded development work and/or supplying products to a few larger systems or instrument companies. Today, many more optics products and suppliers exist, and the industry is a major, separately identifiable industry with companies ranging from large system manufacturers to small companies supplying components, subsystems, and design and engineering services. The optics market and the many markets that incorporate optics are headed toward a strong growth period, driven by a combination of lasers, imaging, display, and image/signal processing technologies that enable new devices, instruments, and systems within markets ranging from health care to communications to aerospace.

The success of optics in penetrating most modern-day systems as an enabling technology has resulted in a strong demand for qualified, invisible professionals. Rarely does a week go by that I do not receive inquiries from former students now in management positions as well as from professional recruiters looking for a few good students. My colleagues at other schools tell similar stories. But this is all anecdotal. What we need to determine the scope of the problem and to devise some policies is some numbers. We need to count the optical engineering jobs, the current professional population, and the students graduating from optics programs. But that is the function of those classifications I listed earlier. You can't count invisible men ... or women.

The existence of optics-relevant occupational classifications would help to define the actual need for specific talents for such job openings, as well as to recruit and retain such talent. First of all, why can't the occupations be added to the standard listings? The Standard Occupational Codes (SOCs) describe individual occupations, not industry classifications. These are the terms that are used extensively in statistical gathering at the federal, state, and local levels. The SOCs are developed within the Labor Department's Bureau of Labor Statistics (BLS). When a question arises as to whether a scientific/engineering/ technical occupation should be added to the SOCs, the BLS normally turns to the NSF for advice and clarifica- 
tion since it is the body that best tracks the trends in science and engineering occupations.

SPIE, OSA, and the Coalition for Photonics and Optics (CPO), which represents more than a dozen optics organizations, got together to see what could be done about getting the occupations in optics listed as SOCs. They petitioned the BLS for inclusion in the listing and the NSF did a search for optics from the database compiled from the most recent National Survey of College Graduates. The NSF designed the survey to provide data on the number and characteristics of individuals with training and/or employment in science and engineering in the United States. The last survey went to a sampling of 215,000 individuals, all of whom had at least a B.S. in a scientific/ engineering discipline. Approximately 80,000 responses were returned. From those 80,000, NSF's search on ' 'optics" (and close derivatives) yielded less than 10 respondents indicating that they considered themselves optical scientists and/or engineers. So, part of the problem lies with ourselves. (Based on the actual wording of the question and its position in the survey, the response to this question did not depend on a list of codes from which the respondent had to choose. Theoretically, the lack of an optical scientist or optical engineer code should not have influenced the person filling out the survey.)

According to Kathi Ream, SPIE's Technology Policy and Government Relations Representative, the Department of Labor regularly sends a survey to 1.2 million employers to gather statistics on job titles, trends, etc. All employers in the United States with 250 or more employees receive the survey; the rest of the recipients comprise a statistically valid sample. Again, there are very few responses to "optics/photonics"' or close derivatives. Based on conversations with the BLS, around 500 responses would automatically trigger a trend review and start the process of incorporating a new category into their statistical gathering. Kathi noted that the NSF and BLS do not believe that they should drive what is or is not an occupation. They see themselves as taking their lead from the marketplace. The categories established and used are based on information that they receive from employers and employees.

What can be done to solve this problem? For one thing, it has not gone unnoticed. The SPIE Engineering, Sci- ence, and Technology Policy (ESTeP) Committee, as well as the CPO, has been considering the problem. It has been one of the few talking points that SPIE members taking part in the annual Congressional Visits Day make to the representatives, senators, and their staff. But aside from increasing the visibility of the problem in Washington, part of the solution exists in our offices and labs. Consider the employment postings at the SPIE Career Centers. They describe open positions in terms we understand and answer to: Optical Engineer, Optical Scientist, Optical Technician, etc. Yet responses to questionnaires by individuals and by companies who hire our types do not reflect these professional designations. This is a heck of a refractive index mismatch. Perhaps we should model our professions with a refractive index of zero: they don't exist ... . even to us!

Why the disconnect? With the NSF survey, it would appear that the respondents who are practicing optical engineers/scientists do not view themselves as such. It is quite likely that when filling out a survey, they tend to list their degree rather than the term that best describes their job in optics. On the BLS side, for most of the surveys, the respondent is probably someone in human resources. It is also quite likely that the responses are based on current job titles as opposed to the descriptions that are in an advertisement, since the wording in ads tends to be broad to elicit a wide selection of candidates. From the work done so far it appears it doesn't take much (as far as response numbers go) to get an internal review triggered. The problem may lie as much within the optics community as it does in the federal government. Next time you get a questionnaire, be careful how you respond. A correct answer might get us to the point where our refractive index is closer to that of BK7.

Note: some of the text was adapted from an issues paper used during a Congressional Visits Day and from a memo analyzing the current situation by Kathi Ream, who I wish to thank for her help.

Donald C. O'Shea Editor 